\title{
Symptom clusters in adults with inflammatory bowel disease
}

\author{
Samantha Conley ${ }^{1}$ (D) | Deborah D. Proctor ${ }^{2}$ | Sangchoon Jeon ${ }^{1}$ | \\ Robert S. Sandler $^{3}$ | Nancy S. Redeker ${ }^{1}$
}

${ }^{1}$ Yale School of Nursing, West Haven, Connecticut

${ }^{2}$ Department of Medicine, Section of Digestive Diseases, Yale University, New Haven, Connecticut

${ }^{3}$ Department of Medicine, Division of Gastroenterology and Hepatology, University of North Carolina, Chapel Hill, North Carolina

Correspondence

Samantha Conley, Yale School of Nursing, PO Box 27399, West Haven 06516, CT.

Email: samantha.conley@yale.edu

Funding information

National Institute of Nursing Research,

Grant number: T32NR008346; Patient-

Centered Outcomes Research Institute,

Grant number: 1501-26653

\begin{abstract}
Symptoms (pain, fatigue, sleep disturbance, depression, and anxiety) in inflammatory bowel disease (IBD) are associated with reduced quality of life. Understanding how IBD symptoms cluster and the clinical and demographic factors associated with symptom clusters will enable focused development of symptom management interventions. The study purposes were to (i) identify symptom cluster membership among adults with IBD and (ii) examine associations between demographic (age, gender, race/ethnicity, and education) and clinical factors (smoking status, time since diagnosis, medication type, IBD type, disease activity), and membership in specific symptom cluster groups. We conducted a retrospective study of data from the Crohn's and Colitis Foundation of America's (CCFA) Partners Cohort and used Patient Reported Outcome Measurement Information System (PROMIS) measures to measure pain interference, fatigue, sleep disturbance, anxiety, and depression. The sample included 5,296 participants with IBD (mean age 44, 72\% female). In latent class analysis (LCA), four groups of participants were identified based on symptoms: "low symptom burden" (26\% of sample), "high symptom burden" (38\%), "physical symptoms" (22\%), and "psychological symptoms" (14\%). In multinomial regression, female gender, smoking, corticosteroids, Crohn's disease, and active disease state were associated with membership in the high symptom burden group. Additional research is needed to test interventions that may be effective at reducing symptom burden for individuals with IBD.
\end{abstract}

\section{KEYWORDS}

inflammatory bowel disease, latent class analysis, PROMIS, symptoms, symptom clusters

\section{I SYMPTOM CLUSTERS IN ADULTS WITH INFLAMMATORY BOWEL DISEASE}

Inflammatory bowel disease (IBD) primarily includes Crohn's disease and ulcerative colitis, afflicts 1.4 million people in the United States, and has increasing incidence rates worldwide (Molodecky et al., 2012). IBD follows an unpredictable course associated with periods of active disease and remission and can lead to complications that lead to the escalation of therapy, hospitalization, and surgery (Loftus, 2004).

IBD is associated with many signs and symptoms, including diarrhea, fever, reduced appetite, weight loss, pain, and fatigue. The most prevalent and distressing symptoms experienced by people with IBD are pain, fatigue, sleep disturbance, depression, and anxiety. Between $58.7 \%$ and $85.5 \%$ of people with IBD experience pain (Ghosh \& Mitchell, 2007; Haapamaki, Turunen, Roine, Farkkila, \& Arkkila, 2008; Haapamaki, Turunen, Roine, Farkkila, \& Arkkila, 2009; Horvath et al., 2012; Magro et al., 2009); 41-48\% experience fatigue (van Langenberg \& Gibson, 2010); 49-77\% experience sleep disturbance (Graff et al., 2011); 25-61\% report depressive symptoms (Guthrie et al., 2002; Magro et al., 2009; Vidal et al., 2008; Zhang et al., 2013); and 31-44\% report anxiety (Guthrie et al., 2002; Vidal et al., 2008). 
People with IBD rate symptoms as major concerns and perceive symptoms to be more distressing than fecal incontinence and the potential development of colon cancer (Czuber-Dochan, Dibley, Terry, Ream, \& Norton, 2012; de Rooy et al., 2001; Stjernman, Tysk, Almer, Strom, \& Hjortswang, 2010). People with IBD are often embarrassed by symptoms that affect career plans and restrict social life (Devlen et al., 2014). Symptom burden contributes to decreased work productivity (Haapamaki et al., 2009; Magro et al., 2009), decreased ability to participate in leisure activities (Ghosh \& Mitchell, 2007; Haapamaki et al., 2009), and reduced quality of life (Ghosh \& Mitchell, 2007; Haapamaki et al., 2008).

Symptoms are more common during periods of active disease, but they frequently persist during remission (Ghosh \& Mitchell, 2007; Graff et al., 2011; Kurina, Goldacre, Yeates, \& Gill, 2001; van Langenberg \& Gibson, 2010), when intestinal inflammation and the associated fever, rectal bleeding, abnormal stool frequency, and fecal urgency are quiescent (Panaccione, Colombel, Louis, Peyrin-Biroulet, \& Sandborn, 2013; Travis et al., 2011). Even during remission, symptoms continue to rank as a top disease-related concern in IBD (Keeton, Mikocka-Walus, \& Andrews, 2015).

Although past research conducted with people who have IBD focused on single symptoms, symptoms co-occur. For example, depression and anxiety were associated with pain (Schirbel et al., 2010), and sleep disturbance was associated with fatigue, depression, anxiety, and abdominal pain (Ananthakrishnan, Long, Martin, Sandler, \& Kappelman, 2013; Banovic, Gilibert, \& Cosnes, 2010; Banovic, Gilibert, Jebrane, \& Cosnes, 2012; Benhayon et al., 2013; Graff et al., 2013; Jelsness-Jorgensen, Bernklev, Henriksen, Torp, \& Moum, 2011). In other chronic inflammatory conditions, such as heart disease and cancer, symptoms occur in clusters (Aktas, Walsh, \& Rybicki, 2010; Dodd, Miaskowski, \& Lee, 2004; Fan, Filipczak, \& Chow, 2007), defined as two or more related symptoms that co-occur (Fan et al., 2007). However, little is known about symptom clusters among people with IBD or the demographic and clinical factors that may be associated with symptom clusters.

Demographic factors associated with individual symptoms in IBD include younger age (Bager et al., 2012) and female gender (Larsson, Loof, Ronnblom, \& Nordin, 2008; Romberg-Camps et al., 2010). Although the potential associations between race and ethnicity and symptoms have not been examined in people with IBD, differences in racial and ethnic group members' perceptions of IBD may influence symptom reporting. For example, these may include differences in attributing disease activity to stress and in informing their support network about their diagnosis (Finlay, Basu, \& Sellin, 2006). Education level is not associated with fatigue (Czuber-Dochan, Ream, \& Norton, 2013), but higher educational attainment is associated with depression in IBD (Fuller-Thomson \& Sulman, 2006).

Evidence on links between clinical factors and symptoms is mixed. Longer disease duration and Crohn's disease (compared to ulcerative colitis; Guthrie et al., 2002) are associated with increased symptoms (Mussell, Bocker, Nagel, \& Singer, 2004). In contrast to people who have ulcerative colitis, people who smoke, and have Crohn's disease may experience fewer symptoms (Mahid, Minor, Soto, Hornung, \&
Galandiuk, 2006; Parkes, Whelan, \& Lindsay, 2014). IBD medications are associated with both increased and decreased symptoms (Haapamaki et al., 2009; Louis et al., 2013). While remission status is associated with reduced symptoms, symptoms can persist during remission (Keeton et al., 2015).

Improved understanding of the nature of symptom clusters and their clinical and demographic correlates is needed to support future interventions focused on managing symptom clusters. This is crucial because treating single symptoms (e.g., depression) may not improve other related symptoms (e.g., sleep disturbance or fatigue; Morrow et al., 2003; Taylor, Walters, Vittengl, Krebaum, \& Jarrett, 2010). Understanding modifiable and non-modifiable risk factors for symptom clusters will also assist in targeting future interventions.

\section{1 | Purpose}

The purposes of this study were to (i) identify symptom cluster membership groups (for symptoms of pain, fatigue, sleep disturbance, depression, and anxiety) among adults with IBD and (ii) examine the associations between demographic (age, gender, race/ethnicity, and education) and clinical factors (smoking status, time since diagnosis, medication type, disease activity), and membership in specific symptom clusters.

\section{2 | METHODS}

\section{1 | Design}

We conducted a retrospective analysis of cross-sectional data obtained from the Crohn's and Colitis Foundation of America (CCFA) Partners Cohort that includes adults who had self-reported IBD and responded to a web-based survey. The CCFA Partners began in 2011 and has ongoing enrollment. It includes participants from all 50 United States, multiple US territories, and several additional countries. Data are collected via an internet survey every 6 months. Full details of the cohort and the data collection methods are reported elsewhere (Long et al., 2012). The University of North Carolina Chapel Hill institutional review board (IRB) approved the original study, and all participants provided written informed consent. The IRB at Yale University determined that the present analysis was exempt due to the use of de-identified data.

\section{2 | Sample}

The CCFA Partners Cohort included 14,314 participants. Participants were 18 years of age or older and had self-reported diagnoses of IBD (Crohn's disease or ulcerative colitis/indeterminate colitis). In a validation study of 184 CCFA Partners participants, $97 \%$ of the selfreported IBD diagnoses were confirmed by a physician (Randall et al., 2013). We excluded participants who had ostomies or j-pouches because the clinical disease activity indices were not created to assess disease activity after these surgical alterations. 
Power analysis methods have yet to be standardized for latent class analysis (LCA), but LCA experts suggest that 100-300 participants are needed to run an LCA model (Collins \& Lanza, 2010; Wurpts \& Geiser, 2014). The study sample included 5,296 participants; therefore, the sample size was adequate for LCA.

\section{3 | Variables and measures}

\subsection{1 | Demographic and clinical characteristics}

Demographic and clinical characteristics were obtained by self-report. Demographic variables included age, race/ethnicity (non-Hispanic white or other) and gender (male or female). Clinical variables included smoking status (never or current/past), duration of IBD (years), current IBD medications (corticosteroids, 5-ASAs, immunomodulators, biologics), and IBD type (Crohn's disease or ulcerative colitis/indeterminate colitis), and clinical remission (yes/no). Self-reported disease activity indices including the Short Crohn's Disease Activity Index (SCDAl; Thia, Faubion, et al., 2011) and the Simple Clinical Colitis Activity Index (SCCAI; Thia, Loftus, et al., 2011; Walmsley, Ayres, Pounder, \& Allan, 1998) were used to differentiate active disease from remission. These clinical indices elicit frequency of bowel movements, the presence of blood in the stool, extra-intestinal manifestations of IBD, and overall health. Scores of $<150$ on the Short Crohn's Disease Activity Index (Thia, Faubion, et al., 2011) and $\leq 2$ on the Simple Clinical Colitis Activity Index (Walmsley et al., 1998) were defined as clinical remission (Thia, Faubion, et al., 2011).

\subsection{2 | Symptoms}

Pain interference, fatigue, sleep disturbance, depression, and anxiety were measured with the Patient Reported Outcomes Measurement Information System (PROMIS) from the National Institutes of Health. These symptoms were selected because they are the most common and distressing symptoms experienced by people with IBD (Ananthakrishnan et al., 2013; Banovic et al., 2010, 2012; Benhayon et al., 2013; Graff et al., 2013; Jelsness-Jorgensen et al., 2011). PROMIS was developed with itemresponse theory, a method that permits for the reduction of a large number of items into a concise unidimensional measure that is highly reliable, precise, and retains statistical power (Fries, Bruce, \& Cella, 2005).

Four-item PROMIS short forms were used to elicit each of the symptoms as occurring over the past 7 days. PROMIS items employ 5 -point Likert scales that range from not at all to very much, with the exception of the pain interference items that include a score of zero for no pain in addition to the 5-point Likert scale. PROMIS measures are scored on a normalized $t$-score based on the general population, with 50 as the mean and 10-point standard deviation increments (National Institutes of Health, 2013).

\subsection{3 | Pain interference}

Items elicited responses about how much pain interfered with the ability to work in the home, perform chores, participate in social activities, and do day-to-day activities. This scale has concurrent validity with the Medical Outcomes Study Short-Form 36 (SF-36) Bodily Pain Scale (Amtmann et al., 2010).

\subsection{4 | Fatigue}

Fatigue items elicit frequency, duration, intensity, and interference characteristics (Cella et al., 2010). The fatigue scale is valid and reliable and has comparable performance to the SF-36 Vitality scale and the Functional Assessment of Chronic Illness Therapy-Fatigue scale (Cella et al., 2010).

\subsection{5 | Sleep disturbance}

Sleep disturbance items are designed to elicit sleep quality, the extent to which sleep was refreshing, difficulty falling asleep, and sleep problems (National Institutes of Health, 2013). The PROMIS Sleep Disturbance scale is valid compared to the Pittsburgh Sleep Quality Index and is better able to discriminate between levels of sleep disturbance (Yu et al., 2011).

\subsection{6 | Depression}

Depression items elicit frequency of feeling depressed, hopeless, worthless, and helpless (Teresi et al., 2009). The PROMIS depression scale is comparable to legacy depression measures, and the absence of somatic items supports its appropriateness for use in chronic health conditions (Pilkonis et al., 2011).

\subsection{7 | Anxiety}

Anxiety items elicit responses about fear, ability to focus on anything other than anxiety, worries, and feeling of unease (National Institutes of Health, 2013). The anxiety measure is valid compared to legacy anxiety measures (Pilkonis et al., 2011).

\subsection{8 | Symptom cut-off scores}

We dichotomized the symptom scores to indicate presence or absence of the symptom because LCA requires the use of categorical indicator variables. Each of the symptom scores was categorized as present $(\geq t$-score of 50 ) or absent $(<50)$ because scores of 50 or higher indicate the presence of a clinically significant symptom (Cella et al., 2014; National Institutes of Health, 2013).

\section{4 | Statistical analysis}

Data were described using distributions, means, medians, standard deviations, and frequencies as appropriate. We compared individual symptoms and disease activity using chi-square analysis and used LCA, a clustering approach that classifies subgroups of people into mutually exclusive and exhaustive groups based on the presence or absence of a characteristic, to determine symptom cluster 
TABLE 1 Demographic and clinical characteristics of the sample $(N=5926)$

\begin{tabular}{|c|c|c|c|c|}
\hline & $M$ & SD & $n$ & $\%$ \\
\hline Age (years) & 44.13 & 15.19 & & \\
\hline \multicolumn{5}{|l|}{ Gender } \\
\hline Female & & & 3,821 & 72.15 \\
\hline Male & & & 1,475 & 27.85 \\
\hline Missing & & & 0 & 0.00 \\
\hline \multicolumn{5}{|l|}{ Race/ethnicity } \\
\hline White non-hispanic & & & 4,599 & 92.33 \\
\hline Other & & & 382 & 7.67 \\
\hline Missing & & & 315 & 5.95 \\
\hline \multicolumn{5}{|l|}{ Education $n$ (\%) } \\
\hline High school or less & & & 369 & 6.97 \\
\hline Some college/college degree & & & 2,934 & 55.40 \\
\hline Graduate school & & & 1,536 & 29.00 \\
\hline Missing & & & 457 & 8.62 \\
\hline \multicolumn{5}{|l|}{ Smoking status } \\
\hline Never & & & 3,341 & 63.09 \\
\hline Ever & & & 1,631 & 30.80 \\
\hline Current & & & 316 & 5.97 \\
\hline Missing & & & 8 & 0.15 \\
\hline Disease duration (years) & 14.42 & 12.92 & & \\
\hline \multicolumn{5}{|l|}{ IBD diagnosis } \\
\hline Crohn's disease & & & 2,992 & 56.50 \\
\hline Ulcerative colitis & & & 1,803 & 34.04 \\
\hline Missing & & & 501 & 9.46 \\
\hline \multicolumn{5}{|l|}{ Medications } \\
\hline 5-ASAs & & & 2,474 & 46.71 \\
\hline Corticosteroids & & & 753 & 14.21 \\
\hline Immunomodulators & & & 1,522 & 28.74 \\
\hline Biologics & & & 1,839 & 34.72 \\
\hline \multicolumn{5}{|l|}{ Disease activity } \\
\hline Remission & & & 2,835 & 53.53 \\
\hline Active disease & & & 2,086 & 39.40 \\
\hline Missing & & & 375 & 7.08 \\
\hline
\end{tabular}

IBD, inflammatory bowel disease; 5-ASAs, 5-aminosalicyclic acids.

membership (Lanza, Collins, Lemmon, \& Schafer, 2007; Vermunt \& Magidson, 2004). We used SAS 9.4 with the PROC LCA \& LTA (Lanza, Dziak, Huang, Wagner, \& Collins, 2015) add-on for SAS from the Methodology Center at Pennsylvania State to conduct the analysis. Significance was set at $p<.05$.

There are two conceptual views of symptom clusters: the grouping of variables (variable-oriented) and the grouping of people (personoriented; Maliski, Kwan, Elashoff, \& Litwin, 2008). Variable-oriented approaches, such as factor analysis, focus on identifying relationships between variables, and researchers assume that these relationships are stable across the population. Person-oriented approaches, such as latent class and cluster analyses, are used to identify subgroups of people who exhibit similar patterns of characteristics. Common person-oriented clustering methods include latent class and cluster analysis (Bergman \& Trost, 2006; Collins \& Lanza, 2010; Conley, 2016). The person-oriented approach is particularly useful in uncovering subgroups in heterogeneous populations because the structure of the variables does not have to remain constant across the population (Magnusson, 2003). Because people with IBD are a heterogeneous population, we used LCA to identify symptom cluster group membership.

The symptoms of pain interference, fatigue, depression, anxiety, and sleep disturbance were categorical indicator variables in the LCA model. We ran models with one, two, three, four, and five classes because these were the number of plausible groups, given the use of five symptom variables. To determine the optimal fit of latent classes with our data, model fit statistics were the Akaike information criterion (AIC; Akaike, 1987), and the Bayesian information criterion (BIC; Schwartz, 1978). AIC and BIC are both relative fit statistics; therefore, no single number indicates best fit. Model fit is determined relative to other models, and lower numbers indicate better fit. We also reported goodness of fit $\mathrm{G}^{2}$ fit statistic, an absolute model fit statistic that does not take the other models into consideration. The goodness of fit $\mathrm{G}^{2} \mathrm{fit}$ statistic follows a chi-square distribution. As is standard with LCA, we also took into account parsimony and interpretability when selecting the final model.

To interpret the final model, we used class prevalences and itemresponse probabilities. Latent class prevalences provide the proportion of people belonging to each class. Item-response probabilities reflect the probability that a group will endorse a particular response. Itemresponse probabilities range from 0 to 1 , and larger numbers indicate a higher probability of a symptom occurring within a particular group (Collins \& Lanza, 2010).

To explore the associations between demographic (age, gender, race/ethnicity, education level) and clinical characteristics (smoking status, time since diagnosis, IBD medications, IBD type, disease activity), and symptom cluster membership, multinomial regression with backward selection using a logit link function was used. Multinomial regression is similar to logistic regression but allows for multiple categorical non-ordered outcomes. All demographic and clinical factors were added into the model, and characteristics that were not statistically significantly linked with a symptom cluster membership group were removed one at a time. Variables for which the $95 \%$ confidence intervals contained one in all of the symptom cluster groups were removed to ensure we had a parsimonious model. The low symptom burden group was the reference group for comparison with the other symptom groups.

Missing data in the LCA model were handled with full-information maximum likelihood (FIML), an imputation method often used in LCA and structural equation modeling. FIML imposes no bias for data missing completely or missing at random and can be used with categorical indicator variables (Enders \& Bandalos, 2001). FIML is superior to case-wise deletion, even when data are not missing at 
TABLE 2 Comparison of symptom reports on disease activity $(n=5296)$

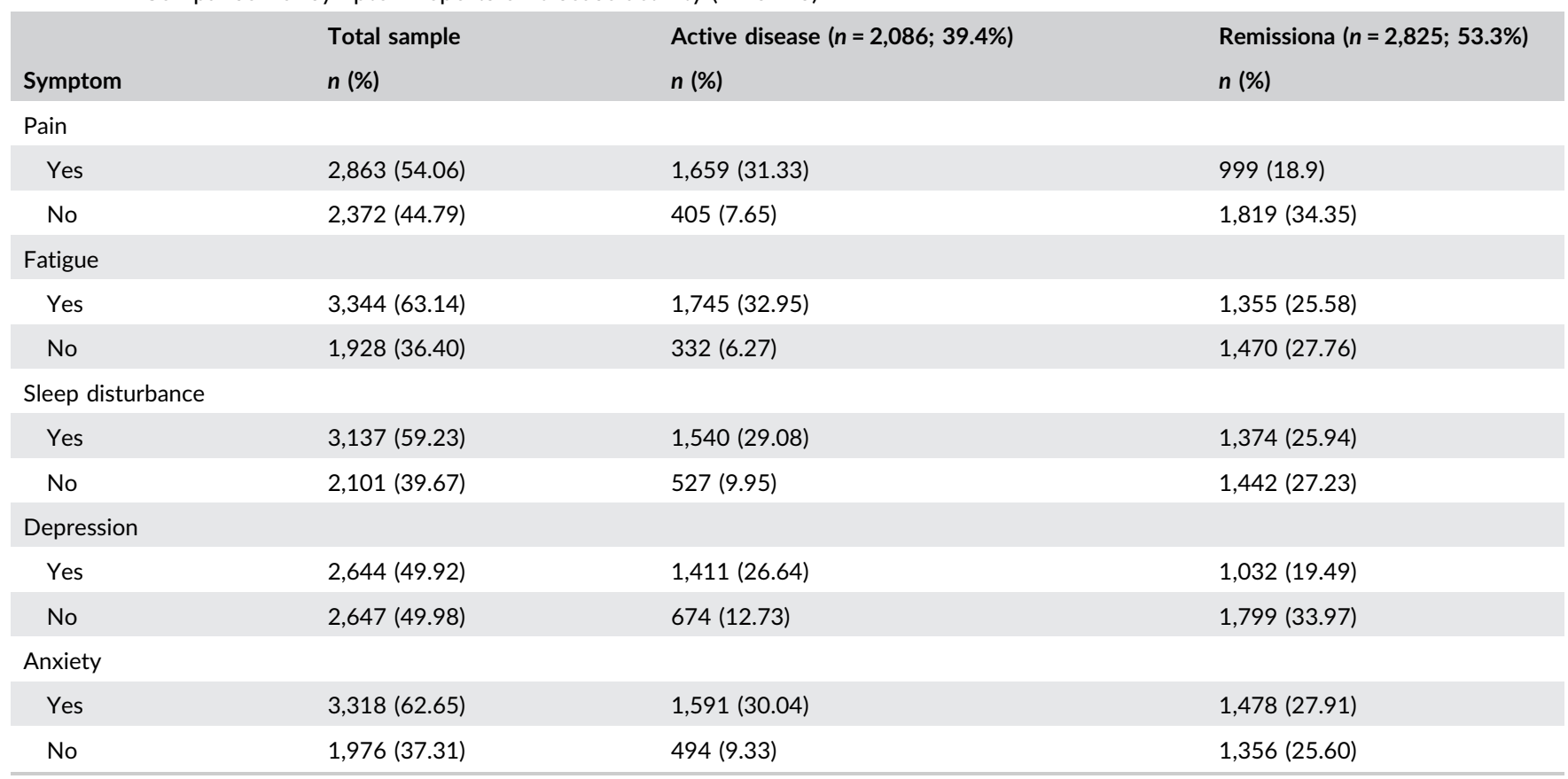

Due to missing data, percentages do not add up to $100 \%$. All group comparisons $p<.001$ in chi-square tests.

${ }^{a}$ Scores of $<150$ on the Short Crohn's Disease Activity Index and $\leq 2$ on the Simple Clinical Colitis Activity Index were defined as clinical remission.

random (Graham, 2009). Due to the limitations of FIML, we excluded cases with missing covariate data, to mirror the approach used in structural equation modeling (Collins \& Lanza, 2010).

\section{3 | RESULTS}

The original CCFA Partners sample included 14,314 participants. We excluded 1,846 who had $\mathrm{j}$-pouches or ostomies or who did not indicate presence or absence of either. We used symptom data from the second CCFA survey (administered between 2012 and 2015) because pain interference was not included in the baseline survey. We excluded 7,172 participants who did not complete the second survey. The final sample included 5,296 participants. Excluded participants had a similar percentage with active disease (39.77\% vs. $39.40 \%)$. However, they were, on average, younger $(M=42.80 \quad[S D=14.68]$ vs. $M=44.13$ years [SD $=15.19]$ years) and had shorter disease duration in years $(M=13.90[S D=12.23]$ vs $M=14.42$ years $[S D=12.92])$ than included participants. Less than $10 \%$ of data were missing for the final sample. Therefore, there was low risk of bias due to missing data (Bennett, 2001).

\section{1 | Demographics, clinical characteristics, and symptoms}

Table 1 includes the clinical and demographic characteristics of the final sample. The mean age of participants was 44.13 years (SD 15.19, range 18-89 years), and the majority of the sample were female (72.15\%) and non-Hispanic white (92.33\%). The mean disease duration was 14.42 years $(S D=12.92$, range $=0-64$ years).

All five symptoms were prevalent, with $54.06 \%$ of participants reporting pain interference, $63.14 \%$ reporting fatigue, $59.23 \%$ reporting sleep disturbance, $49.92 \%$ reporting depressive symptoms, and $62.65 \%$ reporting anxiety. The prevalence of each symptom and the associations of symptoms with disease activity are reported in Table 2. The majority of participants reported two or more symptoms ( $n=3,884 ; 73.33 \%)$, while $13.27 \%(n=703)$ reported one symptom,

TABLE 3 Latent class fit statistics for one to five latent classes of symptoms

\begin{tabular}{|c|c|c|c|c|c|}
\hline Number of latent classes & Log-likelihood & $\mathrm{G}^{2}$ & df & AIC & $\mathrm{BIC}$ \\
\hline 1 & -17759.89 & 5206.58 & 26 & 5216.58 & 5249.45 \\
\hline 2 & -15499.39 & 685.57 & 20 & 707.57 & 779.89 \\
\hline 3 & -15280.48 & 247.75 & 14 & 281.75 & 393.52 \\
\hline $4^{a}$ & -15160.26 & 7.31 & 8 & 53.31 & 204.52 \\
\hline 5 & -15157.84 & 2.46 & 2 & 60.46 & 251.13 \\
\hline
\end{tabular}

AIC, Akaike information criterion; BIC, Bayesian information criterion.

${ }^{a}$ The 4-class solution was selected because AIC and BIC were lowest. 
$12.09 \%(n=640)$ reported no symptoms, and $1.20 \%(n=69)$ were missing data on one or more symptoms.

\section{2 | Symptom clusters}

Participants were grouped into four distinct symptom clusters in LCA based on the presence or absence of each of the symptoms. We selected the four-class solution because it had the lowest AIC and BIC statistics and was parsimonious and clinically relevant. The fit indices for all five models are shown in Table 3. The item-response probabilities for each of the four symptom membership groups by symptom are shown in Table 4.

The first group was labeled "low symptom burden" and included $25.59 \%$ of the participants. It was characterized by a low probability of experiencing pain, fatigue, sleep disturbance, depression, and anxiety. The second and largest group (38.10\% of the sample) was labeled "high symptom burden" and was characterized by a high probability of experiencing pain, fatigue, sleep disturbance, depression, and anxiety. The third group, including $22.09 \%$ of participants, was labeled "physical symptoms," and was characterized by a high probability of experiencing pain, fatigue, and sleep disturbance. The fourth group "psychological symptoms," was the smallest group at $14.22 \%$ and was characterized by a high probability of experiencing anxiety and depression.

\subsection{Demographic and clinical factors associated with symptom cluster group membership}

In developing the multivariable multinomial regression model, current use of immunomodulators ( $p=.56), 5$-ASA $(p=.41)$, biologics $(p=.06)$, completion of some or all college $(p=.06)$, or graduate school $(p=.84)$ compared to high school education or less, and race/ethnicity $(p=.05)$ were dropped in the above order because they were not statistically associated with membership in any symptom cluster group. Younger age, female gender, smoking history, IBD duration, current use of corticosteroids, IBD type, and active disease status were included in the final model. See Table 5 for the estimated odds ratios with $95 \%$ confidence intervals for the associations between the demographic and clinical characteristics, and symptom cluster membership.

Older age was associated with a small decrease in odds of membership (based on magnitude of odds ratios as interpreted by
Chen, Cohen, and Chen (2010) in the psychological symptom cluster group. Female gender and smoking history were associated with a small increase in odds of membership in both the high symptom burden and psychological symptom groups. Longer IBD duration was associated with a small decrease in odds of membership the high symptom burden group. Current use of corticosteroids and a diagnosis of Crohn's disease compared to ulcerative colitis/indeterminate colitis were associated with a medium increase in odds of being in the high symptom burden group and the physical symptoms group. Remission was associated with a medium (psychological symptom group) to large decrease in odds (high symptom burden group and physical symptom group) of being in the high symptom burden, physical, and psychological symptom cluster groups.

\section{4 | DISCUSSION}

To our knowledge, this study was the first to identify symptom cluster group membership among people with IBD. The findings suggest that symptom burden is high among people with IBD, as demonstrated by the fact that nearly $75 \%$ of the sample belonged to a symptom cluster group characterized by at least two symptoms. This result suggests that symptom management may be suboptimal in this population. Although the full implications of the differences between the symptom cluster groups are not known, there is a need to better understand the etiology and consequences of symptom cluster group membership and to consider differences in need for interventions based on symptom cluster group membership. For example, interventions for those with physical versus psychological symptoms are likely to differ. The high symptom cluster burden group may have worse function (e.g., physical function, social function, ability to work) and medical outcomes (e.g., need for surgery, hospitalizations); however, additional research is needed to identify how these outcomes differ with symptom cluster group membership. The clusters found in our study are consistent with previous studies of adults with other common chronic inflammatory conditions, including multiple sclerosis (Shahrbanian, Duquette, Kuspinar, \& Mayo, 2015), cancer (Miaskowski et al., 2015), and heart failure (Lee et al., 2010).

Although remission is associated with decreased symptoms, our finding that nearly half of those in remission reported at least one symptom is consistent with previous research conducted with people

TABLE 4 Prevalence of class membership and response probabilities in four-class model of symptom clusters $(N=5296)$

\begin{tabular}{lllll} 
& Low symptom burden & High symptom burden & Physical symptoms & Psychological symptoms \\
\hline Prevalence & $n=1,355 ; 25.59 \%$ & $n=2,018 ; 38.10 \%$ & $n=1,170 ; 22.09 \%$ & $n=753 ; 14.22 \%$ \\
Pain & .12 & .86 & .66 & .32 \\
Fatigue & .13 & .96 & .78 & .46 \\
Depression & .04 & .90 & .23 & .69 \\
\hline Anxiety & .18 & 1.00 & .27 & 1.00 \\
Sleep disturbance & .24 & .84 & .70 & .45 \\
\hline
\end{tabular}

Bold font indicates symptoms that characterize each class. 
TABLE 5 Demographic and clinical factors associated with symptom cluster group membership $(n=4544)$

\begin{tabular}{|c|c|c|c|c|c|c|}
\hline & \multicolumn{2}{|c|}{ High symptom burden } & \multicolumn{2}{|c|}{ Physical symptoms } & \multicolumn{2}{|c|}{ Psychological symptoms } \\
\hline Age & 0.99 & $(0.98,1.00)$ & 1.02 & $(1.00,1.03)$ & 0.99 & $(0.98,0.99)$ \\
\hline Ever smoker & 1.71 & $(1.30,2.24)$ & 0.87 & $(0.62,1.22)$ & 1.32 & $(1.05,1.66)$ \\
\hline IBD duration (years) & 0.98 & $(0.97,0.99)$ & 0.99 & $(0.97,1.00)$ & 1.00 & $(0.99,1.01)$ \\
\hline Crohn's disease & 5.69 & $(3.81,8.50)$ & 6.33 & $(4.00,10.11)$ & 1.08 & $(0.86,1.36)$ \\
\hline Remission & 0.11 & $(0.01,0.02)$ & 0.03 & $(0.02,0.04)$ & 0.23 & $(0.16,0.38)$ \\
\hline
\end{tabular}

Results of multinomial regression analysis using backwards selection with symptom cluster membership as the outcome. Low symptom burden group was used a reference group. Bold font indicates significant association.

with IBD (Bielefeldt, Davis, \& Binion, 2009; Zhang et al., 2013). Possible reasons for the persistence of symptoms may include sub-clinical inflammation (Berrill, Green, Hood, \& Campbell, 2013), comorbid conditions such as rheumatoid arthritis and irritable bowel syndrome (Ansari et al., 2008), or learned behavior (Kattoor et al., 2013), but none of these variables were included in the CCFA Partners surveys. Studies should be conducted to improve understanding of the etiology of symptoms occurring during both active disease and remission and the factors that may differentiate them.

Crohn's disease was associated with membership in the high symptom burden and physical symptom groups. In contrast to our findings, other researchers found no difference in sleep quality or fatigue between people with Crohn's disease and ulcerative colitis (Graff et al., 2011). Our findings suggest that Crohn's disease may be a risk factor for high symptom burden and warrant focused symptom assessment and management. Additional research is needed to explore the reasons for differences in symptom cluster membership that may be modifiable. For example, nutritional status may differ between Crohn's disease and ulcerative colitis and affect the symptom experience (Bryant, Trott, Bartholomeusz, \& Andrews, 2013).

Our finding that use of corticosteroids was associated with membership in the high symptom burden and physical symptom groups is consistent with previous findings of strong associations between corticosteroid use and anxiety and depression (Loftus et al., 2011). Our findings suggested people with IBD who took corticosteroids did not experience psychological symptoms alone but also experienced physical symptoms. Although corticosteroids are often used to treat active disease, the association between symptom cluster membership and corticosteroids was not fully explained by remission status, suggesting that any persons with IBD taking prescribed corticosteroids may need symptom management.

Female gender was associated with higher odds of belonging to the high symptom burden and psychological symptom cluster groups compared to the low symptom burden cluster group, even with remission taken into account. This result is consistent with previous IBD research in which females were more likely to have more severe symptoms compared to men (Ananthakrishnan et al., 2013; Bager et al., 2012; Walker et al., 2008). Gender differences may be a result of greater symptom awareness among females, differences in perceptions or reporting rates, or biological differences such as menstrual cycle influences (Barsky, Peekna, \& Borus, 2001; Racine et al., 2012). These findings suggest a greater need for symptom management among females, although gender differences need further study.

Smoking history was associated with membership in the high symptom burden and the psychological symptom groups. The relationship between smoking and IBD is complex and somewhat contradictory. For example, smoking is associated with development and worsening of Crohn's disease but protective against development and worsening of ulcerative colitis (Birrenbach \& Bocker, 2004; Parkes et al., 2014). In past research, smoking history was associated with anxiety but not depression among people with IBD (Nahon et al., 2012). In the general population, a history of smoking is related to anxiety and depression, nicotine dependence symptoms and depressive symptoms are often comorbid (Mykletun, Overland, Aaro, Liabo, \& Stewart, 2008), and smoking may increase the risk of depression (Boden, Fergusson, \& Horwood, 2010). Our findings suggest that former and current smokers need additional symptom screening and symptom treatment, especially for psychological symptoms.

While the odds ratio was small, we were surprised to find that longer IBD duration was associated with decreased odds of membership in the high symptom burden cluster group, even when controlling for remission status and corticosteroid use. Although the reasons need further study, people diagnosed with IBD may go through a period of adjustment and adaptation (McCormick et al., 2012) in which they establish new expectations and meanings regarding health (Cooper, Collier, James, \& Hawkey, 2010; Hall, Rubin, Dougall, Hungin, \& Neely, 2005) and become accustomed to symptoms. Learning how to adapt to IBD takes time and experience but becomes part of a normal life (Cooper et al., 2010; Hall et al., 2005). Health care providers can provide active support to IBD patients to help define expectations and experiences to assist in this transition. 


\subsection{Implications for future research}

The etiology of symptom clusters in IBD is unknown. Researchers suggested that symptom clusters in cancer may have a common biological mechanism, including inflammatory cytokines (Cleeland et al., 2003; Illi et al., 2012), hypothalamus-pituitary-adrenal axis (HPA) dysfunction (Kim, Barsevick, Fang, \& Miaskowski, 2012; Thornton, Andersen, \& Blakely, 2010), dysfunctional cognitions and behaviors (Kroenke \& Swindle, 2000), and catastrophizing cognitions (Somers et al., 2009). It is possible that similar mechanisms are responsible for symptoms in people with IBD, a condition that is also inflammatory in nature. There is a need for evaluation of the associations of symptom clusters with biomarkers, such as cytokines (Miaskowski \& Aouizerat, 2012), fecal calprotectin (Vieira et al., 2009), and omics (e.g., inflammatory genes; Illi et al., 2012). This research will increase understanding of the etiology of symptom clusters.

Because symptoms are associated with decreased ability to work and participate in social activities, further research is needed to understand better the full impact of symptom cluster membership on multiple domains of quality of life, including ability to work, and social functioning and health care utilization and costs. These studies will support understanding of the consequences of symptom burden. Subsequent research can follow to determine the effects of interventions to improve symptom burden.

\subsection{Strengths and limitations}

This study has several strengths, including the use of a wellcharacterized cohort and a statistically robust method that is wellsuited for secondary data analysis of symptom clusters (Magidson \& Vermunt, 2003). The large sample enabled us to conduct a wellidentified LCA model, including consideration of several covariates. Use of validated and standardized symptom measures will allow comparison of the results with those of other studies in which these measures were used.

Limitations of this study were the unidimensional nature of the PROMIS measures and the need to dichotomize the symptoms to use LCA. Therefore, we cannot infer severity of single symptoms, frequency, or symptom-associated distress. Reliance on secondary analysis precluded knowledge of participant characteristics that were not collected in the surveys, such as participants' disease location (e.g., ileum, rectum) or use of non-IBD medications (e.g., hypnotics, antidepressants). Another limitation is that diarrhea and fecal incontinence were not included as indicator variables in this study. Diarrhea and fecal incontinence are the predominant signs (objective indicators) of IBD. Diarrhea is a primary indicator in the disease activity indices that were used as a covariate but cannot be teased out of the disease activity indices, as they were not measured consistently between Crohn's disease and ulcerative colitis. Future research is needed to further explore the significance of these signs in IBD. Last, although the use of the internet for data collection allowed a broad geographic representation, it may have limited the racial and ethnic diversity of the sample, which had an overrepresentation of highly educated, non-Hispanic white females. Therefore, the results cannot be generalized to groups that were underrepresented in this cohort.

\section{5 | CONCLUSION}

People with IBD experience high symptom burden. Younger age, female gender, current or past smoking, IBD duration, current use of corticosteroids, Crohn's disease, and remission status were associated with symptom burden. Future research will focus on biomarkers and genetic factors associated with symptom clusters and on the impact of symptom clusters on work and social functioning, health care resource utilization, and costs of health care. In the meantime, healthcare providers should assess for the presence of symptom clusters and offer symptom management where needed.

\section{ACKNOWLEDGMENTS}

This study was funded in part by grants from the National Institutes of Health to the Yale School of Nursing T32 in Self and Family Management (NINR T32NR008346), the Crohn's and Colitis Foundation of America (CCFA), and the Patient Centered Outcomes Research Institute (PCORI).

\section{ORCID}

Samantha Conley (iD) http://orcid.org/0000-0002-4501-5244

\section{REFERENCES}

Akaike, H. (1987). Factor analysis and AIC. Psychometrika, 52, 317-332.

Aktas, A., Walsh, D., \& Rybicki, L. (2010). Symptom clusters: Myth or reality? Palliative Medicine, 24, 373-385. https://doi.org/10.1177/ 0269216310367842

Amtmann, D., Cook, K. F., Jensen, M. P., Chen, W. H., Choi, S., Revicki, D., \& Lai, J. S. (2010). Development of a PROMIS item bank to measure pain interference. Pain, 150, 173-182. https://doi.org/10.1016/j. pain.2010.04.025

Ananthakrishnan, A. N., Long, M. D., Martin, C. F., Sandler, R. S., \& Kappelman, M. D. (2013). Sleep disturbance and risk of active disease in patients with Crohn's disease and ulcerative colitis. Clinical Gastroenterology and Hepatology, 11, 965-971. https://doi.org/10.1016/j. cgh.2013.01.021

Ansari, R., Attari, F., Razjouyan, H., Etemadi, A., Amjadi, H., Merat, S., \& Malekzadeh, R. (2008). Ulcerative colitis and irritable bowel syndrome: Relationships with quality of life. European Journal of Gastroenterology \& Hepatology, 20, 46-50. https://doi.org/10.1097/MEG.0b013e3282 f16a62

Bager, P., Befrits, R., Wikman, O., Lindgren, S., Moum, B., Hjortswang, H., . . Dahlerup, J. F. (2012). Fatigue in out-patients with inflammatory bowel disease is common and multifactorial. Alimentary Pharmacology \& Therapeutics, 35 , 133-141. https://doi.org/10.1111/j.13652036.2011.04914.x

Banovic, I., Gilibert, D., \& Cosnes, J. (2010). Crohn's disease and fatigue: Constancy and co-variations of activity of the disease, depression, anxiety and subjective quality of life. Psychology, Health \& Medicine, 15, 394-405. https://doi.org/10.1080/13548501003759155 
Banovic, I., Gilibert, D., Jebrane, A., \& Cosnes, J. (2012). Personality and fatigue perception in a sample of IBD outpatients in remission: $A$ preliminary study. Journal of Crohn's \& Colitis, 6, 571-577. https://doi. org/10.1016/j.crohns.2011.11.006

Barsky, A. J., Peekna, H. M., \& Borus, J. F. (2001). Somatic symptom reporting in women and men. Journal of General Internal Medicine, 16, 266-275. https://doi.org/10.1046/j.1525-1497.2001.016004266.x

Benhayon, D., Youk, A., McCarthy, F. N., Davis, S., Keljo, D. J., Bousvaros, A., ... Szigethy, E. M. (2013). Characterization of relations among sleep, inflammation, and psychiatric dysfunction in depressed youth with Crohn disease. Journal of Pediatric Gastroenterology and Nutrition, 57, 335-342. https://doi.org/10.1097/MPG.0b013e31829641df

Bennett, D. A. (2001). How can I deal with missing data in my study? Australian and New Zealand Journal of Public Health, 25, 464-469. https://doi.org/10.1111/j.1467-842X 2001. tb00294.x

Bergman, L. R., \& Trost, K. (2006). The person-oriented versus the variableoriented approach: Are they complementary, opposites, or exploring different worlds? Merrill-Palmer Quarterly, 52, 601-631.

Berrill, J. W., Green, J. T., Hood, K., \& Campbell, A. K. (2013). Symptoms of irritable bowel syndrome in patients with inflammatory bowel disease: Examining the role of sub-clinical inflammation and the impact on clinical assessment of disease activity. Alimentary Pharmacology \& Therapeutics, 38, 44-51. https://doi.org/10.1111/apt.12335

Bielefeldt, K., Davis, B., \& Binion, D. G. (2009). Pain and inflammatory bowel disease. Inflammatory Bowel Diseases, 15, 778-788. https://doi.org/ 10.1002/ibd.20848

Birrenbach, T., \& Bocker, U. (2004). Inflammatory bowel disease and smoking: A review of epidemiology, pathophysiology, and therapeutic implications. Inflammatory Bowel Diseases, 10, 848-859. https://doi. org/10.1097/00054725-200411000-00019

Boden, J. M., Fergusson, D. M., \& Horwood, L. J. (2010). Cigarette smoking and depression: Tests of causal linkages using a longitudinal birth cohort. British Journal of Psychiatry, 196, 440-446. https://doi.org/ 10.1192/bjp.bp.109.065912

Bryant, R. V., Trott, M. J., Bartholomeusz, F. D., \& Andrews, J. M. (2013). Systematic review: Body composition in adults with inflammatory bowel disease. Alimentary Pharmacology \& Therapeutics, 38, 213-225. https://doi.org/10.1111/apt.12372

Cella, D., Choi, S., Garcia, S., Cook, K. F., Rosenbloom, S., Lai, J. S., . . . Gershon, R. (2014). Setting standards for severity of common symptoms in oncology using the PROMIS item banks and expert judgment. Quality of Life Research, 23, 2651-2661. https://doi.org/10.1007/s11136-014-0732-6

Cella, D., Riley, W., Stone, A., Rothrock, N., Reeve, B., Yount, S. \& PROMIS Cooperative Group(2010). The patient-reported outcomes measurement information system (PROMIS) developed and tested its first wave of adult self-reported health outcome item banks: 2005-2008. Journal of Clinical Epidemiology, 63, 1179-1194. https://doi.org/10.1016/j. jclinepi.2010.04.011

Chen, H., Cohen, P., \& Chen, S. (2010). How big is a big odds ratio? Interpreting the magnitudes of odds ratios in epidemiological studies. Communications in Statistics-Simulation and Computation, 39, 860-864.

Cleeland, C. S., Bennett, G. J., Dantzer, R., Dougherty, P. M., Dunn, A. J., Meyers, C. A., ... Lee, B. N. (2003). Are the symptoms of cancer and cancer treatment due to a shared biologic mechanism? A cytokineimmunologic model of cancer symptoms. Cancer, 97, 2919-2925. https://doi.org/10.1002/cncr.11382

Collins, L. M., \& Lanza, S. T. (2010). Latent class and latent transition analysis: With applications in the social, behavorial, and health sciences. Hoboken, $\mathrm{NJ}$ : Wiley.

Conley, S. (2016). Symptom cluster research with biomarkers and genetics using latent class analysis. Western Journal of Nursing Research. Advance online publication. https://doi.org/10.1177/0193945916679812

Cooper, J. M., Collier, J., James, V., \& Hawkey, C. J. (2010). Beliefs about personal control and self-management in 30-40 year olds living with inflammatory bowel disease: A qualitative study. International Journal of
Nursing Studies, 47, 1500-1509. https://doi.org/10.1016/j. ijnurstu.2010.05.008

Czuber-Dochan, W., Dibley, L. B., Terry, H., Ream, E., \& Norton, C. (2012). The experience of fatigue in people with inflammatory bowel disease: An exploratory study. Journal of Advanced Nursing, 69, 1987-1999. https://doi.org/10.1111/jan.12060; 10.1111/jan.12060.

Czuber-Dochan, W., Ream, E., \& Norton, C. (2013). Review article: Description and management of fatigue in inflammatory bowel disease. Alimentary Pharmacology \& Therapeutics, 37, 505-516. https://doi.org/ 10.1111/apt.12205.

de Rooy, E. C., Toner, B. B., Maunder, R. G., Greenberg, G. R., Baron, D., Steinhart, A. H., .. Cohen, Z. (2001). Concerns of patients with inflammatory bowel disease: Results from a clinical population. The American Journal of Gastroenterology, 96, 1816-1821. https://doi.org/ 10.1111/j.1572-0241.2001.03877.x

Devlen, J., Beusterien, K., Yen, L., Ahmed, A., Cheifetz, A. S., \& Moss, A. C. (2014). The burden of inflammatory bowel disease: A patient-reported qualitative analysis and development of a conceptual model. Inflammatory Bowel Diseases, 20, 545-552. https://doi.org/10.1097/01.MIB 0000440983.86659 .81

Dodd, M. J., Miaskowski, C., \& Lee, K. A. (2004). Occurrence of symptom clusters. Journal of the National Cancer Institute Monographs, 32, 76-78. https://doi.org/10.1093/jncimonographs/lgh008

Enders, C. K., \& Bandalos, D. L. (2001). The relative performance of full information maximum likelihood estimation for missing data in structural equation models. Structural Equation Modeling, 8, 430-457.

Fan, G., Filipczak, L., \& Chow, E. (2007). Symptom clusters in cancer patients: A review of the literature. Current Oncology, 14(5), 173-179. https://doi.org/10.3747/co.v14i5.140

Finlay, D. G., Basu, D., \& Sellin, J. H. (2006). Effect of race and ethnicity on perceptions of inflammatory bowel disease. Inflammatory Bowel Diseases, 12, 503-507. https://doi.org/10.1097/00054725-200606000-00010

Fries, J. F., Bruce, B., \& Cella, D. (2005). The promise of PROMIS: Using item response theory to improve assessment of patient-reported outcomes. Clinical and Experimental Rheumatology, 23(5 Suppl 39), S53-S57.

Fuller-Thomson, E., \& Sulman, J. (2006). Depression and inflammatory bowel disease: Findings from two nationally representative Canadian surveys. Inflammatory Bowel Diseases, 12, 697-707. https://doi.org/ 10.1097/00054725-200608000-00005

Ghosh, S., \& Mitchell, R. (2007). Impact of inflammatory bowel disease on quality of life: Results of the European Federation of Crohn's and Ulcerative Colitis Associations (EFCCA) patient survey. Journal of Crohn's \& Colitis, 1, 10-20. https://doi.org/10.1016/j.crohns.2007.06.005

Graff, L. A., Clara, I., Walker, J. R., Lix, L., Carr, R., Miller, N., .. Bernstein, C. N. (2013). Fatigue, over time, is associated with disease activity and psychological factors in longitudinal study of inflammatory bowel disease. Clinical Gastroenterology and Hepatology, 11, 1140-1146. https://doi.org/10.1016/j.cgh.2013.03.031

Graff, L. A., Vincent, N., Walker, J. R., Clara, I., Carr, R., Ediger, J., ... Bernstein, C. N. (2011). A population-based study of fatigue and sleep difficulties in inflammatory bowel disease. Inflammatory Bowel Diseases, 17, 1882-1889. https://doi.org/10.1002/ibd.21580

Graham, J. W. (2009). Missing data analysis: Making it work in the real world. Annual Review of Psychology, 60, 549-576. https://doi.org/ 10.1146/annurev.psych.58.110405.085530

Guthrie, E., Jackson, J., Shaffer, J., Thompson, D., Tomenson, B., \& Creed, F. (2002). Psychological disorder and severity of inflammatory bowel disease predict health-related quality of life in ulcerative colitis and Crohn's disease. The American Journal of Gastroenterology, 97, 1994-1999. https://doi.org/10.1111/j. 1572-0241. 2002.05842.x

Haapamaki, J., Turunen, U., Roine, R. P., Farkkila, M. A., \& Arkkila, P. E. (2008). Finnish patients with inflammatory bowel disease have fewer symptoms and are more satisfied with their treatment than patients in 
the previous European survey. Scandinavian Journal of Gastroenterology, 43, 821-830. https://doi.org/10.1080/00365520801912011

Haapamaki, J., Turunen, U., Roine, R. P., Farkkila, M. A., \& Arkkila, P. E. (2009). Impact of demographic factors, medication and symptoms on diseasespecific quality of life in inflammatory bowel disease. Quality of Life Research, 18, 961-969. https://doi.org/10.1007/s11136-009-9514-y

Hall, N. J., Rubin, G. P., Dougall, A., Hungin, A. P., \& Neely, J. (2005). The fight for 'health-related normality': A qualitative study of the experiences of individuals living with established inflammatory bowel disease (IBD). Journal of Health Psychology, 10, 443-455. https://doi. org/10.1177/1359105305051433

Horvath, G., Farkas, K., Hollosi, R., Nagy, F., Szepes, Z., Papp, M., . . Molnar, T. (2012). Is there any association between impaired health-related quality of life and non-adherence to medical therapy in inflammatory bowel disease? Scandinavian Journal of Gastroenterology, 47, 1298-1303. https://doi.org/10.3109/00365521.2012.703233

Illi, J., Miaskowski, C., Cooper, B., Levine, J. D., Dunn, L., West, C., .. Aouizerat, B. E. (2012). Association between pro- and anti-inflammatory cytokine genes and a symptom cluster of pain, fatigue, sleep disturbance, and depression. Cytokine, 58, 437-447. https://doi.org/ 10.1016/j.cyto.2012.02.015

Jelsness-Jorgensen, L. P., Bernklev, T., Henriksen, M., Torp, R., \& Moum, B. A. (2011). Chronic fatigue is more prevalent in patients with inflammatory bowel disease than in healthy controls. Inflammatory Bowel Diseases, 17, 1564-1572. https://doi.org/10.1002/ibd.21530

Kattoor, J., Gizewski, E. R., Kotsis, V., Benson, S., Gramsch, C., Theysohn, N., \& Elsenbruch, S. (2013). Fear conditioning in an abdominal pain model: Neural responses during associative learning and extinction in healthy subjects. PloS ONE, 8(2), e51149. https://doi.org/10.1371/journal.pone.0051149

Keeton, R. L., Mikocka-Walus, A., \& Andrews, J. M. (2015). Concerns and worries in people living with inflammatory bowel disease (IBD): A mixed methods study. Journal of Psychosomatic Research, 78, 573-578. https://doi.org/10.1016/j.jpsychores.2014.12.004

Kim, H. J., Barsevick, A. M., Fang, C. Y., \& Miaskowski, C. (2012). Common biological pathways underlying the psychoneurological symptom cluster in cancer patients. Cancer Nursing, 35(6), E1-E20. https://doi. org/10.1097/NCC.0b013e318233a811.

Kroenke, K., \& Swindle, R. (2000). Cognitive-behavioral therapy for somatization and symptom syndromes: A critical review of controlled clinical trials. Psychotherapy and Psychosomatics, 69, 205-215. https:// doi.org/10.1159/000012395

Kurina, L. M., Goldacre, M. J., Yeates, D., \& Gill, L. E. (2001). Depression and anxiety in people with inflammatory bowel disease. Journal of Epidemiology and Community Health, 55, 716-720. https://doi.org/ 10.1136/jech.55.10.716

Lanza, S. T., Dziak, J. J., Huang, L., Wagner, A., \& Collins, L. M. (2015). PROC LCA \& PROC LTA (version 1.3.2). College Park, PA: Methodology Center, Penn State.

Lanza, S. T., Collins, L. M., Lemmon, D. R., \& Schafer, J. L. (2007). PROC LCA: A SAS procedure for latent class analysis. Structural Equation Modeling, 14, 671-694.

Larsson, K., Loof, L., Ronnblom, A., \& Nordin, K. (2008). Quality of life for patients with exacerbation in inflammatory bowel disease and how they cope with disease activity. Journal of Psychosomatic Research, 64, 139-148. https://doi.org/10.1016/j.jpsychores.2007.10.007

Lee, K. S., Song, E. K., Lennie, T. A., Frazier, S. K., Chung, M. L., Heo, S., . . Moser, D. K. (2010). Symptom clusters in men and women with heart failure and their impact on cardiac event-free survival. The Journal of Cardiovascular Nursing, 25, 263-272. https://doi.org/10.1097/ JCN.0b013e3181cfbb88

Loftus, E. V., Jr (2004). Clinical epidemiology of inflammatory bowel disease: Incidence, prevalence, and environmental influences. Gastroenterology, 126, 1504-1517. https://doi.org/10.1053/j.gastro.2004.01.063

Loftus, E. V., Jr, Guerin, A., Yu, A. P., Wu, E. Q., Yang, M., Chao, J., \& Mulani, P. M. (2011). Increased risks of developing anxiety and depression in young patients with Crohn's disease. The American Journal of Gastroenterology, 106, 1670-1677. https://doi.org/10.1038/ajg.2011.142

Long, M. D., Kappelman, M. D., Martin, C. F., Lewis, J. D., Mayer, L., Kinneer, P. M., \& Sandler, R. S. (2012). Development of an internet-based cohort of patients with inflammatory bowel diseases (CCFA partners): Methodology and initial results. Inflammatory Bowel Diseases, 18, 2099-2106. https://doi.org/10.1002/ibd.22895

Louis, E., Lofberg, R., Reinisch, W., Camez, A., Yang, M., Pollack, P. F., .. . Mulani, P. M. (2013). Adalimumab improves patient-reported outcomes and reduces indirect costs in patients with moderate to severe crohn's disease: Results from the CARE trial. Journal of Crohn's \& Colitis, 7, 34-43. https://doi.org/10.1016/j.crohns.2012.02.017

Magidson, J., \& Vermunt, J. K., (2003). Comparing latent class factor analysis with the traditional approach in data mining. In $\mathrm{H}$. Bozdogan, (Ed.), Statistical data mining \& knowledge discovery. (pp. 373-383). New York, NY: Chapman \& Hall/CRC.

Magnusson, D. (2003). The person approach: Concepts, measurement models, and research strategy. New Directions for Child and Adolescent Development, 101, 3-23. https://doi.org/10.1002/cd.79

Magro, F., Portela, F., Lago, P., Deus, J., Cotter, J., Cremers, I., \& Carvalho, L. (2009). Inflammatory bowel disease: A patient's and caregiver's perspective. Digestive Diseases \& Sciences, 54, 2671-2679. https:// doi.org/10.1007/s10620-008-0658-3

Mahid, S. S., Minor, K. S., Soto, R. E., Hornung, C. A., \& Galandiuk, S. (2006). Smoking and inflammatory bowel disease: A meta-analysis. Mayo Clinic Proceedings, 81, 1462-1471. https://doi.org/10.4065/81.11.1462

Maliski, S. L., Kwan, L., Elashoff, D., \& Litwin, M. S. (2008). Symptom clusters related to treatment for prostate cancer. Oncology Nursing Forum, 35, 786-793. https://doi.org10.1188/08.ONF.786-793

McCormick, J. B., Hammer, R. R., Farrell, R. M., Geller, G., James, K. M., Loftus, E. V., Jr, ... Sharp, R. R. (2012). Experiences of patients with chronic gastrointestinal conditions: In their own words. Health \& Quality of Life Outcomes, 10, 25. https://doi.org/10.1186/1477-7525-10-25

Miaskowski, C., \& Aouizerat, B. E. (2012). Biomarkers: Symptoms, survivorship, and quality of life. Seminars in Oncology Nursing, 28, 129-138. https://doi.org/10.1016/j.soncn.2012.03.008

Miaskowski, C., Dunn, L., Ritchie, C., Paul, S. M., Cooper, B., Aouizerat, B. E., ... Yates, P. (2015). Latent class analysis reveals distinct subgroups of patients based on symptom occurrence and demographic and clinical characteristics. Journal of Pain and Symptom Management, 50, 28-37. https://doi.org/10.1016/j.jpainsymman.2014.12.011

Molodecky, N. A., Soon, I. S., Rabi, D. M., Ghali, W. A., Ferris, M., Chernoff, G., .. Kaplan, G. G. (2012). Increasing incidence and prevalence of the inflammatory bowel diseases with time, based on systematic review. Gastroenterology, 142, 46-54. https://doi.org/10.1053/j.gastro.2011.10.001

Morrow, G. R., Hickok, J. T., Roscoe, J. A., Raubertas, R. F., Andrews, P. L., Flynn, P. J., ... King, D. K. (2003). Differential effects of paroxetine on fatigue and depression: A randomized, double-blind trial from the University of Rochester Cancer Center community clinical oncology program. Journal of Clinical Oncology, 21, 4635-4641. https://doi.org/ 10.1200/JCO.2003.04.070

Mussell, M., Bocker, U., Nagel, N., \& Singer, M. V. (2004). Predictors of disease-related concerns and other aspects of health-related quality of life in outpatients with inflammatory bowel disease. European Journal of Gastroenterology \& Hepatology, 16, 1273-1280.

Mykletun, A., Overland, S., Aaro, L. E., Liabo, H. M., \& Stewart, R. (2008). Smoking in relation to anxiety and depression: Evidence from a large population survey: The HUNT study. European Psychiatry, 23(2), 77-84. https://doi.org/10.1016/j.eurpsy.2007.10.005

Nahon, S., Lahmek, P., Durance, C., Olympie, A., Lesgourgues, B., Colombel, J. F., \& Gendre, J. P. (2012). Risk factors of anxiety and depression in inflammatory bowel disease. Inflammatory Bowel Diseases, 18, 2086-2091. https://doi.org/10.1002/ibd.22888

National Institutes of Health. (2013). PROMIS. Retrieved from http://www. nihpromis.org/ 
Panaccione, R., Colombel, J. F., Louis, E., Peyrin-Biroulet, L., \& Sandborn, W. J. (2013). Evolving definitions of remission in Crohn's disease. Inflammatory Bowel Diseases, 19, 1645-1653. https://doi.org/10.1097/ MIB.0b013e318283a4b3

Parkes, G. C., Whelan, K., \& Lindsay, J. O. (2014). Smoking in inflammatory bowel disease: Impact on disease course and insights into the aetiology of its effect. Journal of Crohn's \& Colitis, 8, 717-725. https://doi.org/ 10.1016/j.crohns.2014.02.002

Pilkonis, P. A., Choi, S. W., Reise, S. P., Stover, A. M., Riley, W. T., Cella, D., \& PROMIS Cooperative Group.(2011). Item banks for measuring emotional distress from the patient-reported outcomes measurement information system (PROMIS ${ }^{\circledR}$ ): Depression, anxiety, and anger. Assessment, 18, 263-283. https://doi.org/10.1177/1073191111411667

Racine, M., Tousignant-Laflamme, Y., Kloda, L. A., Dion, D., Dupuis, G., \& Choiniere, M. (2012). A systematic literature review of 10 years of research on sex/gender and experimental pain perception-Part 1: Are there really differences between women and men? Pain, 153, 602-618. https://doi.org/10.1016/j.pain.2011.11.025

Randall, R. L., Cook, S. F., Wrennnall, C. E., Long, M. D., Chen, W., Martin, C. F., ... Kappelman, M. D. (2013). Validation of an internet-based cohort of patients with inflammatory bowel diseases (CCFA partners). Inflammatory Bowel Diseases, 20, 541-544.

Romberg-Camps, M. J., Bol, Y., Dagnelie, P. C., Hesselink-van de Kruijs, M. A., Kester, A. D., Engels, L. G., .. Stockbrugger, R. W. (2010). Fatigue and health-related quality of life in inflammatory bowel disease: Results from a population-based study in the Netherlands: The IBD-South Limburg cohort. Inflammatory Bowel Diseases, 16, 2137-2147. https:// doi.org/10.1002/ibd.21285

Schirbel, A., Reichert, A., Roll, S., Baumgart, D. C., Buning, C., Wittig, B., .. Sturm, A. (2010). Impact of pain on health-related quality of life in patients with inflammatory bowel disease. World Journal of Gastroenterology, 16, 3168-3177. https://doi.org/10.3748/WJG.v16.i25.3168

Schwartz, G. (1978). Estimating the dimension of a model. The Annals of Statistics, 6, 461-464.

Shahrbanian, S., Duquette, P., Kuspinar, A., \& Mayo, N. E. (2015). Contribution of symptom clusters to multiple sclerosis consequences. Quality of Life Research, 24, 617-629. https://doi.org/10.1007/s11136-014-0804-7

Somers, T. J., Keefe, F. J., Pells, J. J., Dixon, K. E., Waters, S. J., Riordan, P. A., ... Rice, J. R. (2009). Pain catastrophizing and pain-related fear in osteoarthritis patients: Relationships to pain and disability. Journal of Pain and Symptom Management, 37, 863-872. https://doi.org/ 10.1016/j.jpainsymman.2008.05.009

Stjernman, H., Tysk, C., Almer, S., Strom, M., \& Hjortswang, H. (2010). Worries and concerns in a large unselected cohort of patients with Crohn's disease. Scandinavian Journal of Gastroenterology, 45, 696-706. https://doi.org/10.3109/00365521003734141

Taylor, D. J., Walters, H. M., Vittengl, J. R., Krebaum, S., \& Jarrett, R. B. (2010). Which depressive symptoms remain after response to cognitive therapy of depression and predict relapse and recurrence? Journal of Affective Disorders, 123, 181-187. https://doi.org/10.1016/j.jad.2 009.08.007

Teresi, J. A., Ocepek-Welikson, K., Kleinman, M., Eimicke, J. P., Crane, P. K., Jones, R. N., . . Cella, D. (2009). Analysis of differential item functioning in the depression item bank from the Patient Reported Outcome Measurement Information System (PROMIS): An item response theory approach. Psychology Science Quarterly, 51, 148-180.

Thia, K., Faubion, W. A., Jr, Loftus, E. V., Jr, Persson, T., Persson, A., \& Sandborn, W. J. (2011). Short CDAl: Development and validation of a shortened and simplified Crohn's disease activity index. Inflammatory Bowel Diseases, 17, 105-111. https://doi.org/10.1002/ibd.21400

Thia, K. T., Loftus, E. V., Jr, Pardi, D. S., Kane, S. V., Faubion, W. A., Tremaine, W. J., ... Sandborn, W. J. (2011). Measurement of disease activity in ulcerative colitis: Interobserver agreement and predictors of severity. Inflammatory Bowel Diseases, 17, 1257-1264. https://doi.org/10.1002/ibd.21480

Thornton, L. M., Andersen, B. L., \& Blakely, W. P. (2010). The pain, depression, and fatigue symptom cluster in advanced breast cancer: Covariation with the hypothalamic-pituitary-adrenal axis and the sympathetic nervous system. Health Psychology, 29, 333-337. https://doi.org/10.1037/a0018836

Travis, S. P., Higgins, P. D., Orchard, T., Van Der Woude, C. J., Panaccione, R., Bitton, A., ... D'Haens, G. (2011). Review article: Defining remission in ulcerative colitis. Alimentary Pharmacology \& Therapeutics, 34, 113-124. https://doi.org/10.1111/j.1365-2036.2011.04701.x

van Langenberg, D. R., \& Gibson, P. R. (2010). Systematic review: Fatigue in inflammatory bowel disease. Alimentary Pharmacology \& Therapeutics, 32, 131-143. https://doi.org/10.1111/j. 1365-2036. 2010.04347.x

Vermunt, J. K., \& Magidson, J., (2004). Latent class analysis. In M. S. LewisBeck, A. Bryman, \& T. F. Liao, (Eds.), The Sage encyclopedia of social sciences research methods. (pp. 549-553). Thousand Oaks, CA: Sage Publications.

Vidal, A., Gomez-Gil, E., Sans, M., Portella, M. J., Salamero, M., Pique, J. M., \& Panes, J. (2008). Health-related quality of life in inflammatory bowel disease patients: The role of psychopathology and personality. Inflammatory Bowel Diseases, 14, 977-983. https://doi.org/10.1002/ibd.20388

Vieira, A., Fang, C. B., Rolim, E. G., Klug, W. A., Steinwurz, F., Rossini, L. G., \& Candelaria, P. A. (2009). Inflammatory bowel disease activity assessed by fecal calprotectin and lactoferrin: Correlation with laboratory parameters, clinical, endoscopic and histological indexes. BMC Research Notes, 2, 221. https://doi.org/10.1186/1756-0500-2-221

Walker, J. R., Ediger, J. P., Graff, L. A., Greenfeld, J. M., Clara, I., Lix, L., .. . Bernstein, C. N. (2008). The Manitoba IBD cohort study: A populationbased study of the prevalence of lifetime and 12-month anxiety and mood disorders. American Journal of Gastroenterology, 103, 1989-1997. https://doi.org/10.1111/j.1572-0241.2008.01980.x

Walmsley, R. S., Ayres, R. C., Pounder, R. E., \& Allan, R. N. (1998). A simple clinical colitis activity index. Gut, 43(1), 29-32.

Wurpts, I. C., \& Geiser, C. (2014). Is adding more indicators to a latent class analysis beneficial or detrimental? Results of a Monte-Carlo study. Frontiers in Psychology, 5, 920. https://doi.org/10.3389/fpsyg.2014.00920

Yu, L., Buysse, D. J., Germain, A., Moul, D. E., Stover, A., Dodds, N. E., \& Pilkonis, P. A. (2011). Development of short forms from the PROMIS sleep disturbance and sleep-related impairment item banks. Behavioral Sleep Medicine, 10, 6-24. https://doi.org/10.1080/15402002.2012.636266

Zhang, C. K., Hewett, J., Hemming, J., Grant, T., Zhao, H., Abraham, C., ... Proctor, D. D. (2013). The influence of depression on quality of life in patients with inflammatory bowel disease. Inflammatory Bowel Diseases, 19, 1732-1739. https://doi.org/10.1097/MIB.0b013e318281f395

How to cite this article: Conley S, Proctor DD, Jeon S, Sandler RS, Redeker NS. Symptom clusters in adults with inflammatory bowel disease. Res Nurs Health. 2017;1-11. https://doi.org/10.1002/nur.21813 